\title{
Characterization of a ranavirus inhibitor of the antiviral protein kinase PKR
}

Stefan Rothenburg ${ }^{1,2^{*}}$, V Gregory Chinchar ${ }^{3}$, Thomas E Dever ${ }^{1}$

\begin{abstract}
Background: Ranaviruses (family Iridoviridae) are important pathogens of lower vertebrates. However, little is known about how they circumvent the immune response of their hosts. Many ranaviruses contain a predicted protein, designated VIF2 $\alpha$, which shows homology with the eukaryotic translation initiation factor $2 \alpha$. In analogy to distantly related proteins found in poxviruses VIF $2 \alpha$ might act as an inhibitor of the antiviral protein kinase PKR.

Results: We have characterized the function of VIF $2 \alpha$ from Rana catesbeiana virus Z (RCV-Z). Multiple sequence alignments and secondary structure prediction revealed homology of VIF2 $\alpha$ with elF2 $\alpha$ throughout the S1-, helicaland C-terminal domains. Genetic and biochemical analyses showed that vIF $2 \alpha$ blocked the toxic effects of human and zebrafish PKR in a heterologous yeast system. Rather than complementing elF2 $\alpha$ function, VIF2 $\alpha$ acted in a manner comparable to the vaccinia virus (VACV) K3L protein (K3), a pseudosubstrate inhibitor of PKR. Both vIF2 $\alpha$ and K3 inhibited human PKR-mediated elF2 $\alpha$ phosphorylation, but not PKR autophosphorylation on Thr446. In contrast the E3L protein (E3), another poxvirus inhibitor of PKR, inhibited both Thr446 and elF2 $\alpha$ Ser51 phosphorylation. Interestingly, phosphorylation of elF $2 \alpha$ by zebrafish PKR was inhibited by VIF2 $\alpha$ and E3, but not by K3. Effective inhibition of PKR activity coincided with increased PKR expression levels, indicative of relieved autoinhibition of PKR expression. Experiments with VIF2 $\alpha$ deletion constructs, showed that both the N-terminal and helical domains were sufficient for inhibition of PKR, whereas the C-terminal domain was dispensable.
\end{abstract}

Conclusions: Our results show that RCV-Z VIF2 $\alpha$ is a functional inhibitor of human and zebrafish PKR, and probably functions in similar fashion as VACV K3. This constitutes an important step in understanding the interaction of ranaviruses and the host innate immune system.

\section{Background}

Infectious diseases have devastating ecological and economical impacts on fish, amphibian and reptile populations worldwide (reviewed in [1]). Despite those effects, the precise pathogenesis of infectious diseases of ectotherm vertebrates and the interaction with the immune system of their respective hosts are mostly poorly understood. Recently, marked progress has been made in the characterization of the immune system of lower vertebrates. This has been facilitated by concentrated focus on the cloning of pathogen-induced genes and by accumulating sequence data from genome and expressed sequence tag (EST) projects. Similarly, increased information about the genomes of pathogens

\footnotetext{
* Correspondence: sr1hsv@ksu.edu

'Laboratory of Gene Regulation and Development, NICHD, National Institutes of Health, Bethesda, MD 20892, USA

Full list of author information is available at the end of the article
}

of lower vertebrates is becoming available. However, there are still large gaps in our knowledge, especially concerning the interaction of ectothermic pathogens with the host immune system.

Ranaviruses, which constitute a genus within the family Iridoviridae, are important pathogens of ectotherms and have been associated with massive die-offs of both wild and farmed populations of fish, frogs and salamanders in diverse areas of the world [2-5]. Ranaviruses are doublestranded DNA viruses with genomes ranging from 105 to $140 \mathrm{~kb}$. Currently the genomes of seven ranaviruses have been sequenced: Ambystoma tigrinum virus (ATV, accession no. NC_005832[6]); Frog virus 3 (FV3, accession no. NC_005946[7]); Tiger frog virus (TFV, accession no. AF389451 [8]); Grouper iridovirus (GIV,accession no. AY666015 [9]; Singapore grouper iridovirus (SGIV, accession no. NC_006549[10]); Soft-shelled turtle iridovirus (STIV, accession no. EU627010 [11]); and Epizootic
C Biomed Central

(c) 2011 Rothenburg et al; licensee BioMed Central Ltd. This is an Open Access article distributed under the terms of the Creative Commons Attribution License (http://creativecommons.org/licenses/by/2.0), which permits unrestricted use, distribution, and reproduction in any medium, provided the original work is properly cited. 
hematopoietic necrosis virus (EHNV, accession no. FJ433873 [12]). Phylogenetic analysis showed the existence of two major clades among ranaviruses, one that included GIV and SGIV, and another comprised of ATV, EHNV, FV3, STIV and TFV. Interestingly, the latter clade could be further subdivided with ATV and EHNV in one subclade, and FV3, STIV and TFV in the other. The diversity of organisms (amphibians, fish and reptiles) infected by viruses from this second clade, combined with short branch lengths within its two subclades may indicate recent host switches among ranaviruses [12]. However, it should be noted that the host range of ranaviruses is incompletely understood at this time.

The host immune system has evolved multiple ways to fight virus infection and replication. One important arm of the host immune response is the innate immune system, which recognizes molecular patterns present in many pathogens and initiates antimicrobial responses $[13,14]$. An important component of the host response is the antiviral protein kinase PKR, which contains double-stranded (ds) RNA binding domains (RBD) and a kinase domain. PKR is activated by dsRNA, which is formed during infection by many RNA and DNA viruses, and phosphorylates the $\alpha$ subunit of eukaryotic translation initiation factor 2 (reviewed in [15]). PKR is inactive in its latent monomeric form. However, upon binding dsRNA, two PKR molecules dimerize and undergo autophosphorylation on residue Thr446 (for human PKR) [16-18]. Activated PKR then phosphorylates eIF $2 \alpha$ on Ser51, which subsequently acts as an inhibitor of the guanine nucleotide exchange factor eIF2B. As eIF2B normally exchanges GDP for GTP on eIF2, a step necessary for successful translation initiation, eIF2 $\alpha$ phosphorylation leads to a general inhibition of translation initiation $[19,20]$. The function of mammalian PKR and its interaction with viruses has been extensively characterized (reviewed in [15]). However, PKR-like molecules in ectotherms eluded molecular characterization until recently. PKR-like activity was first described in fish cells [21,22]. This was followed by the cloning and functional characterization of crucian carp and zebrafish PKR-related genes, which contain Z-DNA binding $(Z \alpha)$ domains instead of the dsRBDs and were hence named PKZ [23,24]. PKZ was subsequently described in Atlantic salmon and the rare minnow $[25,26]$. Recently, authentic PKR genes were described and characterized in many ectotherm species including zebrafish, pufferfish, Japanese flounder and two Xenopus species [27,28]. Like mammalian PKR, both PKZ and PKR are induced by immunostimulation $[23,27,28]$. Phylogenetic analyses indicate that a duplication of an ancestral PKR-like gene in the fish lineage probably led to the emergence of PKR and PKZ in a fish ancestor, and might have helped to extend the spectrum of viral nucleic acids that can be recognized [27]. Although higher vertebrates lack $\mathrm{PKZ}$ genes, they contain a different $\mathrm{Z} \alpha$-containing protein, termed ZBP1, which binds $Z$-DNA and has been implicated in the recognition of viral DNA and the induction of an antiviral response [29-31].

In order to overcome the antiviral effects of PKR many mammalian viruses encode inhibitors of PKR, which block PKR activation or activity at different steps during or following the activation process (reviewed in [32]). Many poxviruses possess two PKR inhibitors, which are designated E3 and $\mathrm{K} 3$ in vaccinia virus (VACV) and are encoded by the E3L and K3L genes, respectively. E3 binds to dsRNA and prevents activation of PKR [33,34], whereas K3 encodes an S1 domain that is homologous to the N-terminus of eIF2 $\alpha$ and inhibits activated PKR by binding to the kinase domain and acting as a pseudosubstrate inhibitor of PKR [18,35,36].

Interestingly, most ranaviruses encode a protein with an $\mathrm{S} 1$ domain, which is related to the S1 domain of eIF $2 \alpha$ and K 3 and is referred to as a viral homolog of eIF $2 \alpha$ or vIF $2 \alpha$. In contrast to K3, which only possesses the $\mathrm{S} 1$ domain, vIF $2 \alpha$ proteins contain a C-terminal extension of between 165 to 190 amino acids, for which no sequence homology to any other proteins was described. It was previously speculated that vIF $2 \alpha$ in analogy to $\mathrm{K} 3$ might be an inhibitor of PKR and might therefore play an important role in the pathogenesis of ranaviruses [37-39]. Herein, using a heterologous yeast assay system, we describe the characterization of vIF $2 \alpha$ as an inhibitor of human and zebrafish PKR.

\section{Results}

We present three lines of evidence that the C-terminus of vIF2 $\alpha$ is actually homologous to the helical and parts of the C-terminal domains of eIF2 $\alpha$. Firstly, we performed PSI-BLAST searches with vIF $2 \alpha$ from ATV and RCV-Z. During the first iteration, sequence similarity for regions spanning amino acids 5-118 of ATV-vIF2 $\alpha$ with the S1 and helical domains eIF2 $\alpha$ from multiple eukaryotes was noted. During the second iteration, this region of similarity to eIF2 $\alpha$ was extended to amino acid position 253 of vIF $2 \alpha$. Secondly, multiple sequence alignments including vIF $2 \alpha$ from many ranaviruses and eIF $2 \alpha$ from a diverse set of eukaryotes showed conservation of amino acids outside the S1 domain: 8 amino acids are 100\% conserved among the sequences (Figure 1, red background; Cys99, Glu118, Leu160, Ala177, Gly192, Ala199, Val220 and Gly253). Moreover, conservative amino acid differences are present at 22 positions outside the S1 domain (Figure 1, green background). At many other positions, amino acids that are identical to the ones found in vIF2 $\alpha$ are present in a subset of eIF $2 \alpha$ sequences (Figure 1, light blue background). While the multiple sequence 


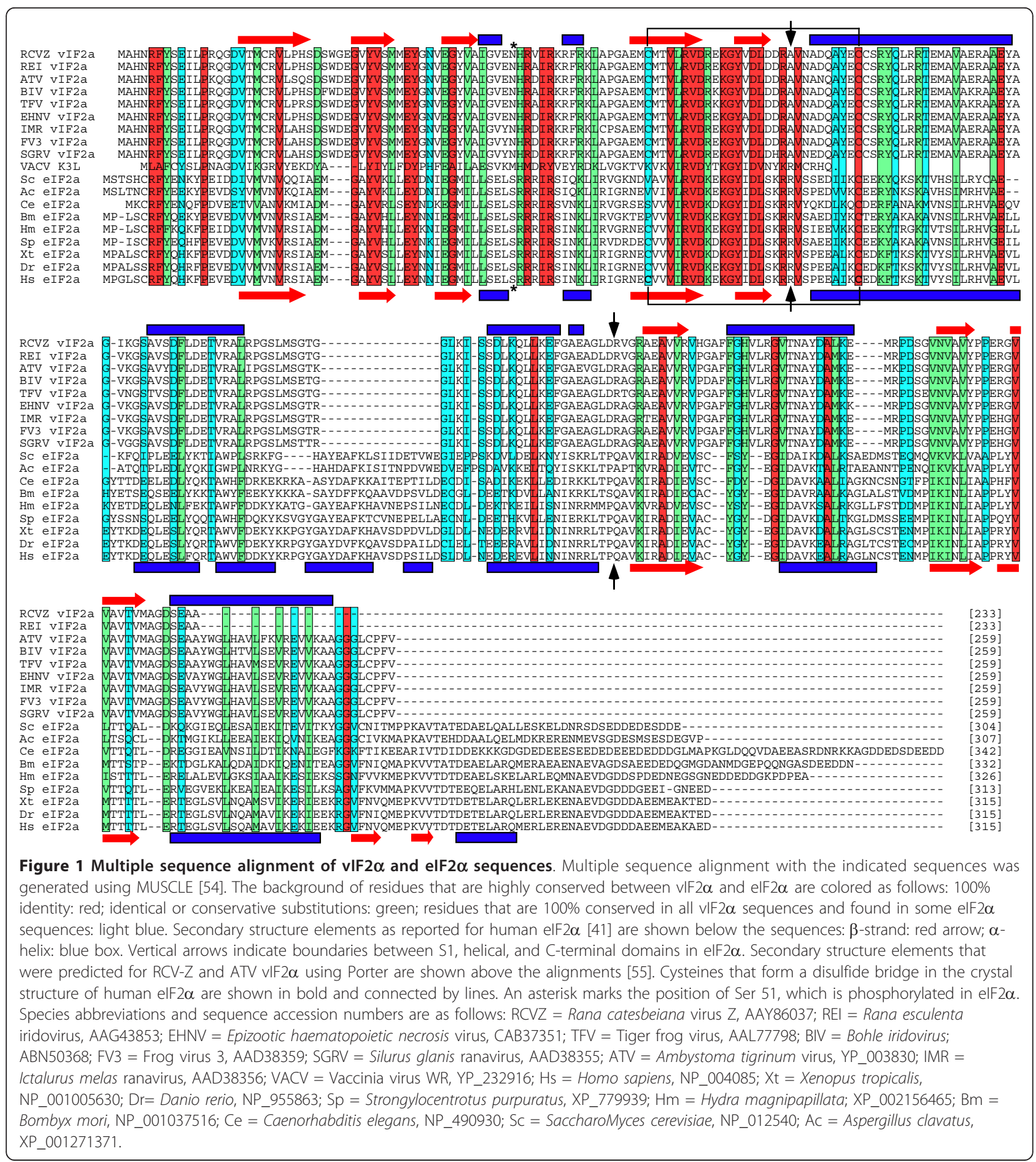

alignment reveals sequence homology between vIF $2 \alpha$ and eIF2 $\alpha$ throughout the reading frame, sequence similarity is highest within the S1 domain, with the highest levels of sequence identity surrounding strands $\beta 4$ and $\beta 5$ (Val74 - Leu88 in vIF2 $\alpha$ ) as previously described $[38,39]$. Interestingly, in VACV K3 this region was previously shown to be important for PKR inhibition [40]. Thirdly, secondary structure prediction with ATV and RCV-Z vIF $2 \alpha$ resulted in predicted $\beta$-sheets and $\alpha$-helices that coincide very well with the solved structural features observed in the NMR structure of human eIF2 $\alpha$ [41]. These observations indicate that the middle and C-terminal parts of vIF2 $\alpha$ are homologous to the helical and Cterminal domains, respectively, of eIF $2 \alpha$. 
Yeast-based assays were previously employed to characterize PKR and its interaction with viral inhibitors $[34,40,42,43]$. To test whether vIF $2 \alpha$ can inhibit PKRmediated toxicity in yeast, we transformed a control strain and a strain expressing human PKR under the control of the galactose-regulated GAL-CYC1 hybrid promoter with plasmids designed to express $\mathrm{RCV}-\mathrm{Z}$ vIF2 $\alpha$ and VACV K3L also under control of the GAL$C Y C 1$ promoter. When grown under inducing conditions (galactose medium), comparable growth was seen in the control strain transformed with vector, $\mathrm{K} 3 \mathrm{~L}$ or vIF $2 \alpha$, demonstrating that K 3 and vIF $2 \alpha$ had no effect on yeast cell growth (Figure $2 \mathrm{~A}$ ). In contrast, induction of PKR expression was toxic in the vector-transformed yeast, whereas the toxicity was suppressed by co-expression of K3L or vIF2 $\alpha$ (Figure 2B).

Based on the homology of vIF2 $\alpha$ with eIF $2 \alpha$ throughout the entire ORF we tested whether suppression of PKR toxicity might be caused by the complementation of eIF $2 \alpha$ function by vIF $2 \alpha$. To this end, we transformed a yeast strain that carries a temperature-sensitive mutant of eIF2 $\alpha$ (sui2-1) [44] with an empty vector, with a plasmid designed to express wild-type eIF2 $\alpha$ (SUI2) under
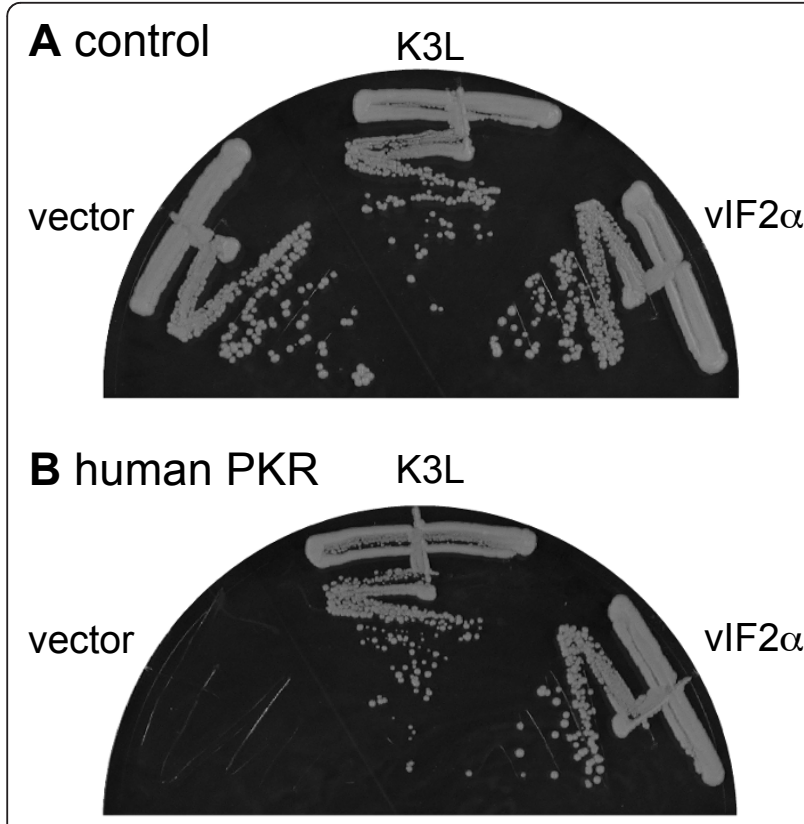

Figure 2 vIF $2 \alpha$ inhibits human PKR-mediated toxicity in yeast. Plasmids expressing VACV K3L (pC140) or RCV-Z VIF2 $\alpha$ (pC3853) under the control of a yeast GAL-CYC1 hybrid promoter, or the vector pEMBLyex4 alone, were introduced into isogenic yeast strains having either an empty vector (A, control, J673) or a GAL-CYC1human PKR construct $(B$, J983) integrated at the LEU2 locus. The indicated transformants were streaked on SC-Gal medium where expression of both PKR and the viral proteins was induced, and incubated at $30^{\circ} \mathrm{C}$ for 4 days. Results shown are representative of 4 independent transformants for each plasmid. the control of its native promoter, or with the plasmids that express vIF2 $\alpha$ or K3L under the control of the galactose regulated $G A L-C Y C 1$ promoter. Yeast transformants were streaked on synthetic complete medium containing galactose (SC-Gal) and incubated at different temperatures. At permissive temperatures $\left(27^{\circ} \mathrm{C}\right.$ and $30^{\circ} \mathrm{C}$ ) all transformants grew well (Figure 3). However, when incubated at restrictive temperatures $\left(33^{\circ} \mathrm{C}\right.$ and $36^{\circ} \mathrm{C}$ ), only wild type eIF $2 \alpha$ was able to rescue growth

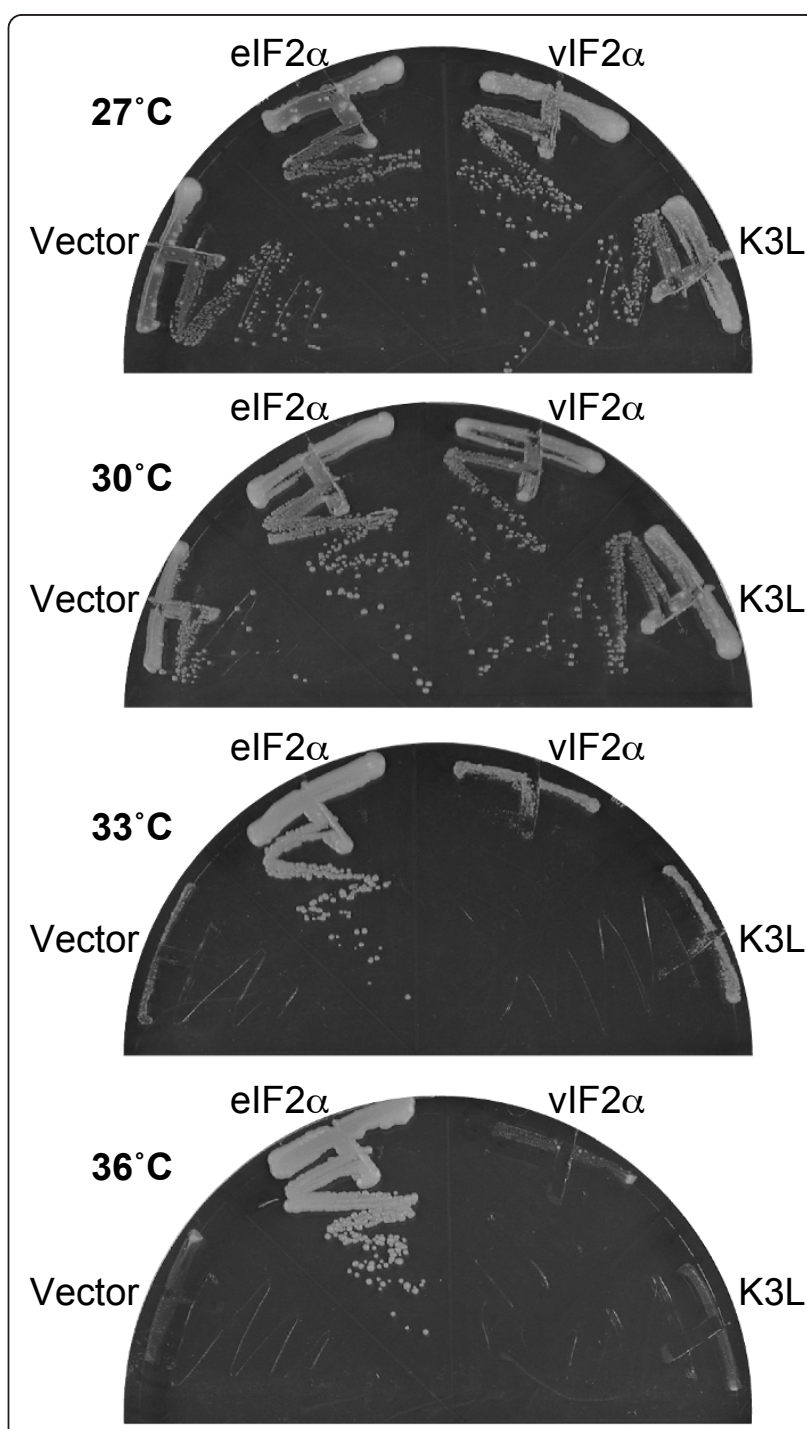

Figure 3 vIF $2 \alpha$ does not complement elF $2 \alpha$ function in yeast. Plasmids expressing VACV K3L (pC140) or RCV-Z vIF2 $\alpha$ (pC3853) under the control of a yeast GAL-CYC1 hybrid promoter, or yeast elF2 $\alpha$ (p919) under the control of its native promoter, or the vector pEMBLyex4, were introduced into the temperature-sensitive elF2 $\alpha$ (sui2-1, TD304-10B) mutant strain. The indicated transformants were streaked on SC-Gal medium, where elF $2 \alpha$ expression was maintained and the viral protein expression was induced, and incubated at the indicated temperatures. Results shown are representative of 4 independent transformants for each plasmid. 
(Figure 3). It is important to note that under these growth conditions vIF2 $\alpha$ and K3L were able to suppress PKR toxicity (data not shown), indicating that the viral proteins are functional under these conditions. As expression of neither vIF $2 \alpha$ nor K3L suppressed the growth defects of the sui2-1 mutant strain, we conclude that vIF $2 \alpha$ does not functionally substitute for eIF $2 \alpha$.

We next compared the effect of vIF $2 \alpha$ on human and zebrafish PKR with the effects of the two VACV PKR inhibitors $\mathrm{K} 3$ and E3. In the control strain not expressing PKR, expression of K3L or vIF2 $\alpha$ had no effect on yeast cell growth, whereas expression of E3L induced a slow growth phenotype as previously described [34] (Figure 4A). The toxicity associated with expression of human PKR was inhibited by co-expression of $\mathrm{K} 3 \mathrm{~L}$, vIF $2 \alpha$ or E3L (Figure 4B). Interestingly, the toxicity associated with expression of zebrafish PKR in yeast was only inhibited by vIF $2 \alpha$ or E3L, but not by K3L (Figure $4 \mathrm{C}$ ). Thus in accord with the virus host range vIF2 $\alpha$, but not VACV K3L, may have evolved to inhibit fish PKR. To assess the effectiveness of K3, E3, and vIF $2 \alpha$ to inhibit human and zebrafish PKR, matching sets of strains expressing a particular inhibitor and either no PKR, human PKR, or zebrafish PKR were streaked on the same plate for comparison. Examining the colony sizes of the transformants in the streaks revealed that K3 did not fully inhibit human PKR (colonies of cells expressing human PKR plus K3L were smaller than colonies expressing $\mathrm{K} 3 \mathrm{~L}$ and no PKR, Additional file 1: Figure S1A). In contrast, vIF2 $\alpha$ and E3 appeared to fully inhibit both human and zebrafish PKR (Additional file 1: Figure S1B, C).

Suppression of PKR toxicity in yeast could be due to impaired PKR expression or due to inhibition of eIF $2 \alpha$ phosphorylation. In order to examine eIF $2 \alpha$ phosphorylation, yeast whole cell extracts were prepared by the TCA method to prevent protein degradation and dephosphorylation, and Western blot analyses were performed using phospho-specific antibodies directed against phospho-Ser51 in eIF $2 \alpha$. To normalize for protein loading, the blot was then stripped and probed with anti-yeast eIF2 $\alpha$ antiserum. As shown in Figure 4D (next to bottom panel), induction of either human or zebrafish PKR expression in the absence of a viral inhibitor led to high levels of eIF2 $\alpha$ phosphorylation. Co-expression of K3L, vIF $2 \alpha$, or E3L greatly reduced eIF $2 \alpha$ phosphorylation in cells expressing human PKR (Figure 4D and Additional file 2: Figure S2). Consistent with the growth assays, vIF2 $\alpha$ and E3, but not K3, inhibited eIF2 $\alpha$ phosphorylation in yeast expressing zebrafish PKR. Next, PKR expression levels were monitored using an anti-Flag tag antibody. Expression levels of PKR were higher in the presence of effective eIF $2 \alpha$ phosphorylation inhibitors. As observed previously PKR autoinhibits its own expression in yeast $[34,40,45]$. Presumably PKR phosphorylation of eIF $2 \alpha$ leads to suppression of total protein synthesis including PKR expression. Accordingly, inhibition of PKR by the viral inhibitors restores protein synthesis and leads to higher PKR levels. Taken together, the results of the PKR expression and eIF $2 \alpha$ phosphorylation studies demonstrate that vIF $2 \alpha$ can effectively inhibit eIF $2 \alpha$ phosphorylation by human and zebrafish PKR.

In the presence of effective eIF $2 \alpha$ phosphorylation inhibitors, PKR migrated faster on SDS-PAGE than in the controls (Figure 4D, top panel, lanes 2-4 versus 1 and lanes $7-8$ versus 5 ). This might have been caused by inhibition of PKR autophosphorylation. To examine PKR autophosphorylation, we probed the Western blots with a phospho-specific antibody that recognizes human PKR phosphorylated on Thr446. High levels of Thr446 phosphorylation were detected in the absence of inhibitors and when either K3 or vIF2 $\alpha$ were present. Thr446 phosphorylation was effectively inhibited in the presence of E3 (Figure 4D, second panel, lanes 1-4). These results indicate that $\mathrm{K} 3$ and vIF2 $\alpha$ are unable to block Thr446 phosphorylation and are consistent with previous findings that K3 binding to PKR is dependent on Thr446 phosphorylation [18]. Presumably vIF $2 \alpha$, like K3, binds to PKR following autophosphorylation on Thr446 and blocks subsequent autophosphorylation events that lead to altered mobility of PKR on SDS-PAGE. Zebrafish PKR was not detected with the antibody directed against Thr446-phosphorylated human PKR (Figure 4D, second panel, lanes 5-8). This was expected because of the strong sequence divergence between human and zebrafish PKR surrounding the phosphorylation site [27]. Finally, using yeast growth rate assays as described above, vIF2 $\alpha$ was found to inhibit, at least partially, both Xenopus laevis PKR1 and zebrafish PKZ (data not shown). However, precise determination of PKR1 and PKZ sensitivity to vIF2 $\alpha$ inhibition will depend on the ability to obtain yeast strains expressing the appropriate level of each kinase.

In order to test which domains of vIF2 $\alpha$ are important for PKR inhibition we tested various vIF $2 \alpha$ deletion mutants for their ability to inhibit PKR activity. Additionally, the C-terminus of RCV-Z vIF $2 \alpha$ was extended to match the length of ATV vIF2 $\alpha$ (see Figure 1). For the latter constructs, the $26 \mathrm{C}$-terminal amino acids found in ATV vIF2 $\alpha$ that are not in RCV-Z vIF2 $\alpha$ due to an early termination codon were appended to the C-terminus of RCV-Z vIF $2 \alpha$ (vIF $2 \alpha+26 C$, Figure $5 \mathrm{~A}$ ). None of the vIF $2 \alpha$ constructs led to a growth defect in the control strain not expressing PKR (Figure 5B). In a zebrafish PKR-expressing strain, wild-type vIF2 $\alpha$, vIF2 $\alpha$ $+26 \mathrm{C}$, and vIF $2 \alpha \Delta 59 \mathrm{C}$ (lacking the C-terminal 59 amino acids) led to comparable inhibition of PKR toxicity 


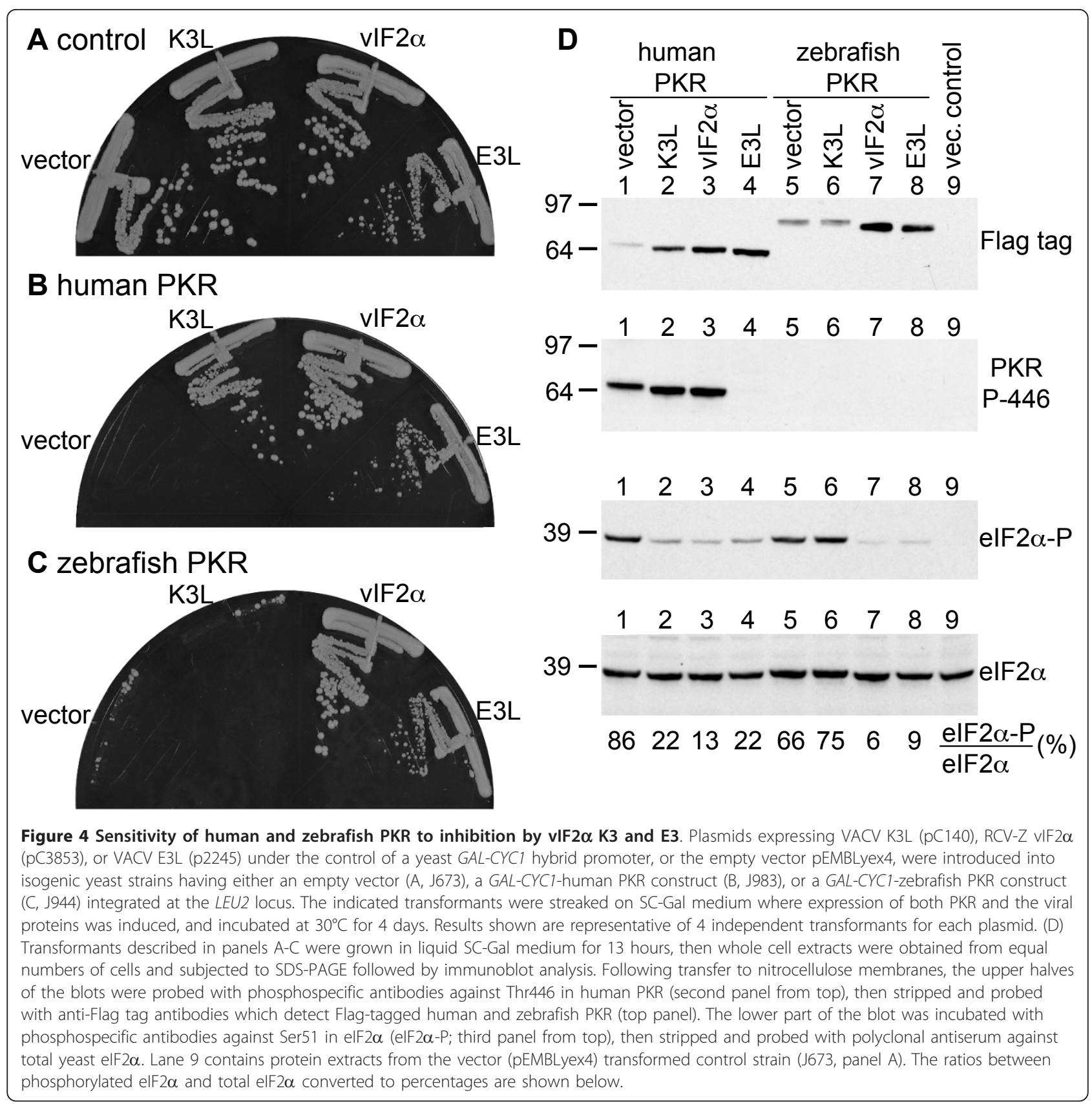

(Figure 5C, sectors 2-4 versus 1 ). In contrast, no PKR suppression was observed when the helical domain was partly (vIF $2 \alpha \Delta 94 \mathrm{C}$ ) or completely (vIF2 $\alpha \Delta 138 \mathrm{C}$ ) deleted or when the $\mathrm{N}$-terminus was deleted (vIF2 $\alpha$ $\Delta 94 \mathrm{~N}$ and vIF2 $\alpha \Delta 94 \mathrm{~N}+26 \mathrm{C}$ ) (Figure $5 \mathrm{C}$, sectors $5-8$ ). Western analyses of eIF $2 \alpha$ phosphorylation in the strains expressing zebrafish PKR and the various vIF $2 \alpha$ mutants revealed that vIF $2 \alpha$, vIF $2 \alpha+26 C$, vIF $2 \alpha 59 \mathrm{C}$ led to strong and comparable inhibition of eIF $2 \alpha$ phosphorylation (Figure 5D, next to bottom panel, lanes 2-4). Consistent with their inability to inhibit PKR toxicity in yeast, high levels of eIF $2 \alpha$ phosphorylation were observed in strains expressing the other vIF2 $\alpha$ mutants (Figure 5D). As seen earlier, PKR was expressed at higher levels and migrated faster on SDS-PAGE when PKR toxicity and eIF $2 \alpha$ phosphorylation were suppressed (Figure 5D, top panel). Western blot analyses using antibodies against a $\mathrm{C}$-terminal Myc-epitope tag in the vIF $2 \alpha$ constructs revealed detectable expression for only vIF $2 \alpha$, vIF $2 \alpha+26 C$, and vIF $2 \alpha 59$ C. Comparable results were obtained in Western blot analyses of protein extracts from the control (-PKR) strain expressing 


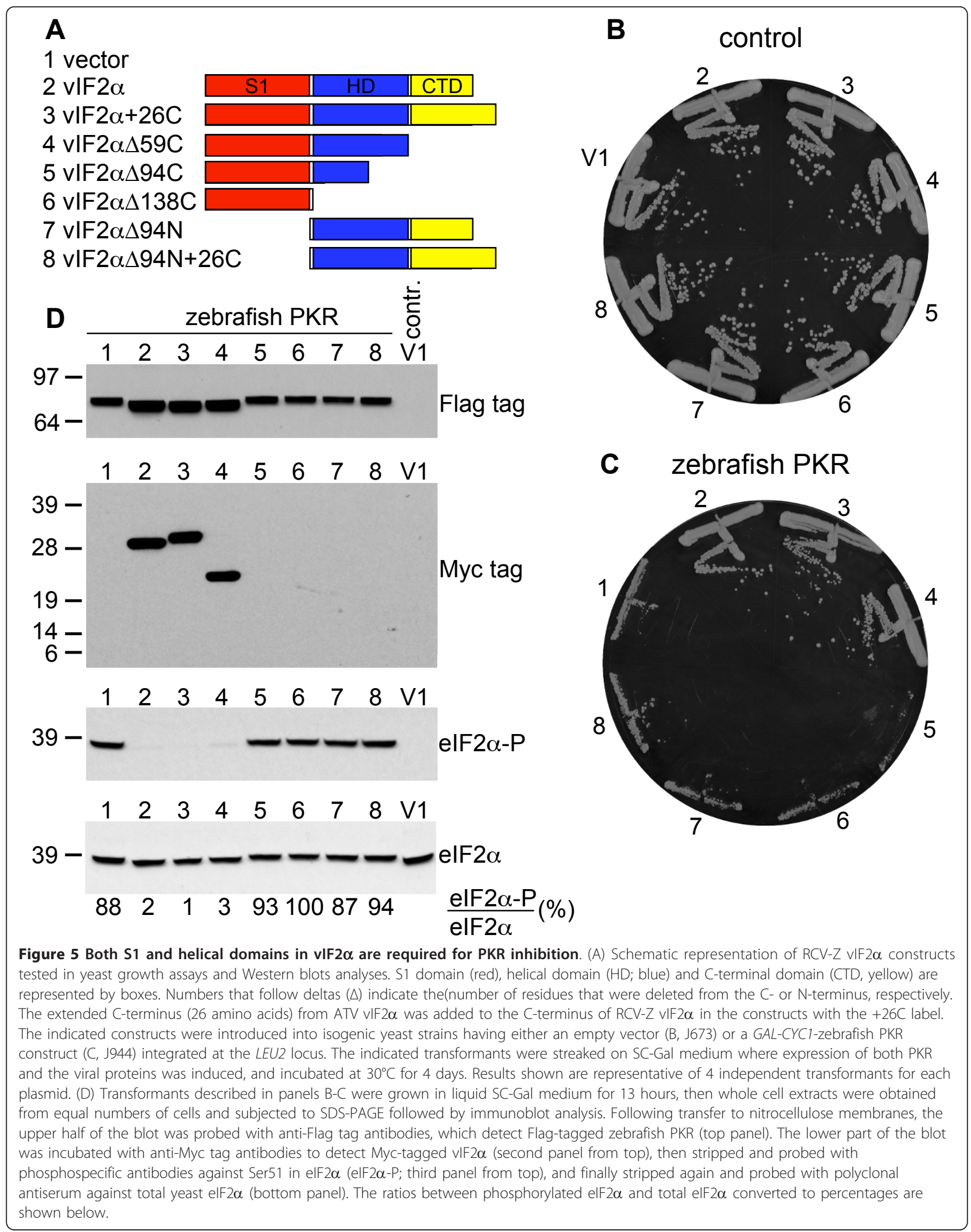


these same vIF $2 \alpha$ mutants (data not shown), indicating that both the S1 domain and the helical domain are essential for vIF $2 \alpha$ expression and/or stability.

\section{Discussion}

Ranaviruses are important pathogens of fish, amphibians and reptiles (reviewed in [2]). However, little is known about how they interact with the immune system of their hosts. Herein we show that RCV-Z vIF2 $\alpha$, a homo$\log$ of eIF $2 \alpha$, is an effective inhibitor of PKR in a heterologous yeast assay system. PKR is an important antiviral protein kinase that has been primarily studied in mammals (reviewed in [15]). PKR-related genes have recently been identified in a variety of fish and amphibian species. Fish PKR genes are expressed at low levels constitutively, but they are highly induced after viral infection and stimulation with the dsRNA analog poly(I:C), which mimics viral infection $[27,28]$. It was recently shown that PKR of the Japanese flounder (Paralichthys olivaceus) was able to inhibit replication of Scophthalmus maximus rhabdovirus [28]. To date, only PKR inhibitors from mammalian viruses have been functionally characterized (reviewed in [32]). Moreover, the only well-characterized viral PKR inhibitors that directly target the PKR kinase domain are the pseudosubstrates found in many poxviruses and represented by VACV K3L, which is homologous to the $\mathrm{S} 1$ domain of the PKR target eIF2 $\alpha[33,40,46,47]$. It was speculated that the ranavirus vIF $2 \alpha$ protein, another eIF $2 \alpha$ homolog, might inhibit PKR of infected hosts [38,39]. A notable difference between $\mathrm{K} 3$ and eIF $2 \alpha$ is the presence of an extended $\mathrm{C}$-terminal domain in eIF $2 \alpha$. In addition to the C-terminal $\alpha / \beta$ domain, eIF $2 \alpha$ consists of an $\mathrm{N}$-terminal S1 domain and a central $\alpha$-helical domain. The K3 protein is homologous to the $\mathrm{N}$-terminal domain in eIF $2 \alpha$. Like K3, vIF $2 \alpha$ shows moderate sequence identity to eIF $2 \alpha$ in the S1 domain. In this study we used PSI-BLAST analyses, multiple sequence alignment and secondary structure prediction to show that the $\mathrm{C}$-terminal parts of vIF $2 \alpha$ are likewise homologous to the helical and Cterminal domains of eIF2 $\alpha$.

Functional analyses using deletion constructs of vIF $2 \alpha$ revealed that both the S1 and helical domains are sufficient for inhibition of PKR in yeast (Figure 5). Since the presence of both domains was necessary for detectable vIF2 $\alpha$ expression, it appears possible that the domains are important to stabilize each other. The crystal structure of human eIF $2 \alpha$ showed that the S1 and helical domains are connected by an intramolecular disulfide bridge formed by cysteine residues 69 and 97 [48]. Interestingly, a cysteine corresponding to position 69 is found in many Metazoa, including Chordata, Echinodermata, Cnidaria and Mollusca, but is missing in most Arthropoda (except Ioxedes scapularis), in all fungi and plants sequences currently found in Genbank, and in all poxviral K3L orthologs (Figure 1 and data not shown). As cysteines corresponding to residues 69 and 97 in human eIF $2 \alpha$ are found in all vIF $2 \alpha$ sequences (Figure 1), we speculate that formation of a disulfide bridge between the two domains might be important for the stability of vIF $2 \alpha$. Future in vitro kinase assays with vIF2 $\alpha$ constructs that are produced in a cell-free translation system might be suited to further investigate the importance of the individual domains.

It is striking that eIF $2 \alpha$ sequences and all known vIF $2 \alpha$ sequences display a high level of sequence identity within their respective groups. The sequence identity for eIF $2 \alpha$ is between $92 \%$ and $100 \%$ among vertebrates, while the sequence identity for vIF $2 \alpha$ is between $95 \%$ and $98 \%$ among ranaviruses. In contrast, K3L orthologs are very diverse, some of which display only around $30-40 \%$ sequence identity to each other [49]. The high sequence conservation in eIF $2 \alpha$ and vIF $2 \alpha$ indicates that eIF $2 \alpha$ might be under purifying (negative) selective pressure in order to maintain its primary sequence or, alternatively, that current ranaviruses might have experienced bottlenecks in their recent evolution. Overall the S1 domains of vIF $2 \alpha$ and $\mathrm{K} 3$ are comparably distantly related to eIF $2 \alpha$.

Interestingly, some Ranaviruses do not encode functional vIF $2 \alpha$ orthologs. GIV and SGIV do not contain vIF $2 \alpha$ orthologs, and truncated vIF $2 \alpha$ genes lacking regions of the $\mathrm{N}$-terminal and the helical domains are found in the completely sequenced FV3 strain and in STIV $[7,11]$. As our studies indicate that the $\mathrm{N}$-terminus of vIF2 $\alpha$ is essential for PKR inhibition, these complete or partial deletions might lead to the attenuation of the viruses. In accord with this notion FV3, which lacks most of vIF $2 \alpha$, is much less pathogenic than RCV-Z in North American bullfrog (Rana catesbeiana) tadpoles [39]. Alternatively the absence of predicted functional vIF $2 \alpha$ proteins in some ranaviruses suggests that, as in vaccinia virus, a second PKR inhibitor may be present in ranaviruses.

Western blot analyses showed that human PKR was expressed at higher levels in yeast expressing the PKR inhibitors vIF $2 \alpha, \mathrm{K} 3 \mathrm{~L}$, or E3L, consistent with the notion that the viral inhibitors suppress autoinhibition of PKR expression. Moreover, PKR from cells expressing viral inhibitors migrated faster on SDS-PAGE, suggesting that the inhibitors might block PKR autophosphorylation. Thr446 is the only site in the human PKR kinase domain that is stoichiometrically phosphorylated and visible in the PKR crystal structure, where it is thought to stabilize the active PKR conformation $[18,50]$. Once activated, PKR can phosphorylate eIF $2 \alpha$ as well as autophosphorylate other residues in the kinase [17,34]; however the significance of the latter is not fully 
understood. Interestingly, only E3L was able to prevent Thr446 phosphorylation. In cells expressing K3L or vIF2 $\alpha$, Thr446 was phosphorylated to the level observed in the absence of an inhibitor, whereas PKR mobility was comparable to that in E3L transformed cells. A likely explanation is that K3 and vIF $2 \alpha$ bind after the initial Thr446 autophosphorylation and block subsequent phosphorylation events. This is in agreement with the finding that activated WT PKR, but not the PKRT446A mutant, was able to bind K3 [18].

Like human PKR, zebrafish PKR was inhibited by E3 and vIF2 $\alpha$. Moreover, as was seen for human PKR, zebrafish PKR from cells expressing the inhibitors migrated faster on SDS-PAGE, indicative of blocked secondary phosphorylation events. An interesting difference between human and zebrafish PKR is that zebrafish PKR was resistant to $\mathrm{K} 3$ inhibition in both the growth and eIF $2 \alpha$ phosphorylation assays. In accord with our previous studies on PKR inhibition by K3 [49], we propose that K3L might have evolved to suppress PKR of the natural poxvirus hosts and that zebrafish PKR is too different to be targeted with high efficiency. It is not clear why vIF $2 \alpha$, which is found in amphibian and fish viruses, can inhibit both human and zebrafish PKR, but it is possible that vIF2 $\alpha$ targets more conserved residues in the PKR kinase domain than does K3. Previously we showed that $\mathrm{K} 3$ exhibits species specificity for inhibition of PKR. Whereas human PKR was only moderately inhibited by VACV K3, mouse PKR was much more sensitive [49]. This difference in sensitivity was attributed to residues that were subject to positive selection during evolution. Interestingly, positive selection was also observed in the kinase domains of fish and amphibian PKR and fish PKZ [49]. It will be interesting to determine whether vIF $2 \alpha$ also shows altered specificity for PKR or the related PKZ of the species that are naturally infected with vIF $2 \alpha$-containing ranaviruses.

\section{Conclusions}

Overall, it appears that vIF2 $\alpha$ and K3 inhibit PKR in a similar fashion, by acting as pseudosubstrates and inhibiting PKR following kinase activation. As vIF2 $\alpha$ does not act as an eIF2 $\alpha$ substitute, but instead inhibits PKR function, the renaming of vIF $2 \alpha$ might be considered. We suggest changing the name from vIF $2 \alpha$ to RIPR, the acronym for Ranavirus Inhibitor of Protein kinase $R$.

\section{Methods}

\section{Yeast strains and plasmids}

Human (hs) and zebrafish (dr) PKR cDNAs containing both N-terminal His6- and Flag tags were first cloned into the yeast expression vector pYX113 (R\&D systems) under the control of a GAL-CYC1 hybrid promoter [27]. Next, the two DNA fragments containing the GAL-CYC1 promoter and a PKR cDNA were subcloned into the LEU2 integrating vector pRS305, which was then directed to integrate into the leu2 locus of the strain H2557

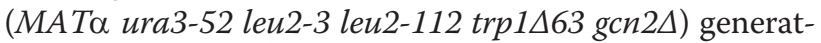
ing the strains $\mathrm{J} 983$ (MAT $\alpha$ ura3-52 leu2-3 leu2-112 $\operatorname{trp} 1 \triangle 63 \operatorname{gcn} 2 \Delta<$ GAL-CYC1-hsPKR, LEU2 >) and 044

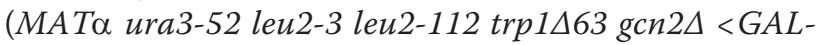
CYC1-drPKR, LEU2 >). Construction of the control

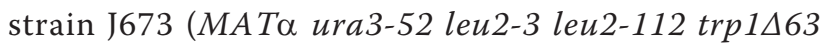
$\operatorname{gcn} 2 \Delta<L E U 2>$ ) was described previously [51]. The temperature-sensitive eIF2 $\alpha$ strain TD304-10B (MAT $\alpha$ his4303 ura3-52 leu2-3 leu2-112 sui2-1) is a derivative of the previously described sui2-1 strain 117-8AR20 [44].

A DNA fragment encoding RCV-Z vIF2 $\alpha$ [39] was amplified by PCR using viral DNA as a template and primers C27 (5' - TAGGATCCAAAATGGCACACAACAGGTTTTAC-3') and C28 (5'- TAAAGTCGACCGCC GCCTCAGAGTCGCCGG-3'). The PCR product was then subcloned between the $\mathrm{BamH}$ I and $\mathrm{Sal}$ I restrictions sites of a modified version of the yeast expression vector pEMBLyex4 that contains two Myc tags at the C-terminal end of the multiple cloning site ( $\mathrm{pC} 3852)$ generating the plasmid pC3853. The following primer combinations were used for cloning of vIF2 $\alpha$ mutant constructs: vIF $2 \alpha \Delta 59 \mathrm{C}$ : C27 plus C29 (5' - TAAAGTCGACCCGACCGACTCT GTCGAGGC-3'); vIF2 $\alpha \Delta 94 \mathrm{C}$ : C27 plus C30 (5'-TAAAGT CGACTCTCAGGGCCCTCACGGTCTC-3'); vIF $2 \alpha \Delta$ 138C: C27 plus C31 (5'-TAAAGTCGACCTGATCGGCATTCAC GGC-3'); vIF2 $\alpha+26 C$ : C27 plus C32 (5'-TAA AGTCGACCACAAAGGGGCACAGTCCTC-3'); vIF2 $\alpha$ $\triangle 94 \mathrm{~N}$ : C33 (5'- TAGGATCCAAAATGGCCGATCAGGC GTACGAGTG-3') plus C28; and vIF $2 \alpha \Delta 94 N+26 C$ : C33 plus C32. The plasmid template for vIF $2 \alpha+26 C$ and vIF $2 \alpha \Delta 94 \mathrm{~N}+26 \mathrm{C}$ was generated by fusion PCR using vector primer C23 (5'- CATATGGCATGCATGTGCTCTG3') plus primer C21 (5'- GCCTTTACGACCTCTCGCA CCTCAGACAGCACGGCGTGCAGTCCCCAGTAC GCCGCCTCAGAGTCGCCG-3') for the first PCR and primer C22 (5'- GTGCGAGAGGTCGTAAAGGCTGC CGGGGGAGGACTGTGCCCCTTTGTGTA AGTCGACCTGCAGGCATGC-3') plus vector primer C24 (5'CGCTTCCGAAAATGCAACGC-3') for the second PCR. Following PCR purification, the two PCR products were mixed and used as a template for PCR along with the vector primers A46F (5'-ATTCTTTCCTTATACATTAGGTCC-3') and A20R (5'-TGCTGCCACTCCTC AATTGG-3'). Finally, the PCR products were cloned into the BamHI and SalI sites of pEMBLyex4. All PCRs were carried out using Pfu Polymerase (Stratagene) and all plasmids were sequenced to verify correct sequences. Derivatives of pEMBLyex4 expressing VACV K3L (pC140) and VACV E3L (p2245), as well as the low copy-number SUI2, URA3 plasmid p919 were described previously $[34,40,52]$. 
Yeast strains were transformed using the LiAcetate/ PEG transformation method. For each transformation, four independent colonies were analyzed by streaking on inducing medium, SC-Gal minus uracil (synthetic complete medium containing $2 \%$ galactose and all amino acids, but lacking uracil) and grown at $30^{\circ} \mathrm{C}$ if not otherwise indicated.

\section{Protein expression and Western Blot analyses}

Yeast transformants were grown to saturation in $2 \mathrm{ml}$ of SD medium. This starter culture was diluted 1:50 in 25 $\mathrm{ml} \mathrm{SD}$ medium and grown to $\mathrm{OD}_{600}=0.6$ and then shifted to SC-Gal medium to induce expression. After 13 hours, ODs of the cultures were measured and carefully adjusted by dilution in water to obtain comparable ODs and thus to lyse equivalent amounts of cells for each sample. Whole-cell extracts (WCEs) were prepared using the trichloroacetic acid (TCA) method as described previously [53] and then suspended in $200 \mu \mathrm{l}$ $1.5 \times$ loading buffer with reducing agent (both Invitrogen) and neutralized by the addition of $100 \mu \mathrm{l} 1 \mathrm{M}$ Tris base. Samples $(5 \mu \mathrm{l})$ were fractionated on $10 \%$ Bis-Tris gels (Invitrogen), run in MOPS buffer (Invitrogen), and then transferred to nitrocellulose membranes. Upper parts of the membranes were incubated with rabbit phosphospecific anti-human PKR Thr446 antibodies (21st Century Biochemicals) and then stripped and probed with anti-D (Flag) tag antibody (Applied Biological Materials). Lower halves of the membranes were incubated with an anti-Myc tag antibody (Applied Biological Materials), rabbit phosphospecific antibodies directed against phosphorylated Ser51 of eIF2 $\alpha$ (BioSource International), or rabbit polyclonal antiserum against total yeast eIF $2 \alpha$ Immune complexes were detected using enhanced chemiluminescence. Band intensities were quantified by densitometry using ImageJ http://rsbweb.nih.gov/ij/ and ratios between phosphorylated eIF2 $\alpha$ and total eIF2 $\alpha$ were calculated.

\section{Multiple sequence alignment and secondary structure prediction}

Multiple sequence alignments of all sequences shown in Figure 1 plus all poxvirus K3L orthologs listed in [49] were performed using MUSCLE [54]. Secondary structure predictions for RCV-Z and ATV vIF2 $\alpha$ sequences were performed using Porter [55].

\section{Additional material}

Additional file 1: Figure S1 Comparison of colony sizes of PKRexpressing and control stains expressing K3L, VIF2 $\alpha$ or E3L. Plasmids expressing VACV K3L (A, pC140), RCV-Z VIF2 $\alpha$ (B, pC3853), or VACV E3L (C, p2245) under the control of a yeast GAL-CYC1 hybrid promoter were introduced into isogenic yeast strains having either an empty vector (J673), a GAL-CYC1-human PKR construct (hsPKR, J983), or a GAL-CYC1- zebrafish PKR construct (drPKR, J944) integrated at the LEU2 locus. The indicated transformants were streaked on SC-Gal medium where expression of both PKR and the viral proteins was induced, and incubated at $30^{\circ} \mathrm{C}$ for 4 days. Results shown are representative of 4 independent transformants for each plasmid.

Additional file 2: Figure S2 Relative PKR-induced elF2 $\alpha$ phosphorylation levels after expression of vIF $2 \alpha, \mathrm{K} 3 \mathrm{~L}$ or E3L. Using data from Figure $4 \mathrm{D}$ and an independent experiment, the band intensities of phosphorylated and total elF2 $\alpha$ obtained from Western blots of TCA extracts of yeast cells expressing either human or zebrafish PKR and transformed with an empty vector or plasmids expressing K3L, VIF $2 \alpha$ or E3L, as indicated, were measured using ImageJ. The ratios of phosphorylated and total elF2 $\alpha$ bands were calculated. Standard deviations from the two independent experiments are shown, and significant differences, as calculated using a t-test and as compared to the vector controls $(p<0.05)$, are shown. n. s. $=$ non significant.

\section{Acknowledgements}

We thank Alan Hinnebusch and members of the Dever and Hinnebusch labs for helpful discussions and Tom Donahue for yeast strains. This work was supported in part by the Intramural Research Program of the National Institutes of Health, NICHD.

\section{Author details}

${ }^{1}$ Laboratory of Gene Regulation and Development, NICHD, National Institutes of Health, Bethesda, MD 20892, USA. ²Division of Biology, Kansas State University, Manhattan, KS 66506, USA. ${ }^{3}$ Department of Microbiology, University of Mississippi Medical Center, Jackson, MS 39216, USA.

\section{Authors' contributions}

SR and TED devised this study with important input from VGC. All experiments were performed by SR. The manuscript was drafted by SR with essential contributions from TED and VGC. All authors read and approved the final manuscript.

Received: 20 December 2010 Accepted: 18 March 2011 Published: 18 March 2011

\section{References}

1. Essbauer S, Ahne W: Viruses of lower vertebrates. J Vet Med B Infect Dis Vet Public Health 2001, 48:403-475.

2. Williams T, Barbosa-Solomieu V, Chinchar VG: A decade of advances in iridovirus research. Adv Virus Res 2005, 65:173-248.

3. Whittington RJ, Becker JA, Dennis MM: Iridovirus infections in finfish critical review with emphasis on ranaviruses. J Fish Dis 2010, 33:95-122.

4. Chinchar VG, Hyatt A, Miyazaki T, Williams T: Family Iridoviridae: poor viral relations no longer. Curr Top Microbiol Immunol 2009, 328:123-170.

5. Chinchar VG, Storfer A: Ecology of viruses infecting ectothermic animals The impact of ranavirus infections on amphibians. In Viral Ecology. 2 edition. Edited by: Hurst C. Wiley-Blackwell Publishing; 2011, Viral Ecology.

6. Jancovich JK, Mao J, Chinchar VG, Wyatt C, Case ST, Kumar S, Valente G, Subramanian S, Davidson EW, Collins JP, Jacobs BL: Genomic sequence of a ranavirus (family Iridoviridae) associated with salamander mortalities in North America. Virology 2003, 316:90-103.

7. Tan WG, Barkman TJ, Gregory Chinchar V, Essani K: Comparative genomic analyses of frog virus 3, type species of the genus Ranavirus (family Iridoviridae). Virology 2004, 323:70-84.

8. He JG, Lu L, Deng M, He HH, Weng SP, Wang XH, Zhou SY, Long QX, Wang XZ, Chan SM: Sequence analysis of the complete genome of an iridovirus isolated from the tiger frog. Virology 2002, 292:185-197.

9. Tsai CT, Ting JW, Wu MH, Wu MF, Guo IC, Chang CY: Complete genome sequence of the grouper iridovirus and comparison of genomic organization with those of other iridoviruses. J Virol 2005, 79:2010-2023.

10. Song WJ, Qin QW, Qiu J, Huang CH, Wang F, Hew CL: Functional genomics analysis of Singapore grouper iridovirus: complete sequence determination and proteomic analysis. J Virol 2004, 78:12576-12590.

11. Huang Y, Huang X, Liu H, Gong J, Ouyang Z, Cui H, Cao J, Zhao Y, Wang X, Jiang Y, Qin Q: Complete sequence determination of a novel reptile 
iridovirus isolated from soft-shelled turtle and evolutionary analysis of Iridoviridae. BMC Genomics 2009, 10:224.

12. Jancovich JK, Bremont M, Touchman JW, Jacobs BL: Evidence for multiple recent host species shifts among the Ranaviruses (family Iridoviridae). $J$ Virol 2010, 84:2636-2647.

13. Kumagai $Y$, Takeuchi $O$, Akira S: Pathogen recognition by innate receptors. J Infect Chemother 2008, 14:86-92.

14. Ranjan P, Bowzard JB, Schwerzmann JW, Jeisy-Scott V, Fujita T, Sambhara S: Cytoplasmic nucleic acid sensors in antiviral immunity. Trends $\mathrm{Mol}$ Med 2009, 15:359-368.

15. Toth AM, Zhang P, Das S, George CX, Samuel CE: Interferon action and the double-stranded RNA-dependent enzymes ADAR1 adenosine deaminase and PKR protein kinase. Prog Nucleic Acid Res Mol Biol 2006, 81:369-434.

16. Nanduri S, Rahman F, Williams BR, Qin J: A dynamically tuned doublestranded RNA binding mechanism for the activation of antiviral kinase PKR. Embo J 2000, 19:5567-5574.

17. Zhang F, Romano PR, Nagamura-Inoue T, Tian B, Dever TE, Mathews MB, Ozato K, Hinnebusch AG: Binding of double-stranded RNA to protein kinase PKR is required for dimerization and promotes critical autophosphorylation events in the activation loop. J Biol Chem 2001, 276:24946-24958.

18. Dey M, Cao C, Dar AC, Tamura T, Ozato K, Sicheri F, Dever TE: Mechanistic link between PKR dimerization, autophosphorylation, and elF2alpha substrate recognition. Cell 2005, 122:901-913.

19. Rowlands AG, Panniers R, Henshaw EC: The catalytic mechanism of guanine nucleotide exchange factor action and competitive inhibition by phosphorylated eukaryotic initiation factor 2. J Biol Chem 1988, 263:5526-5533.

20. Dever TE, Yang W, Astrom S, Bystrom AS, Hinnebusch AG: Modulation of tRNA(iMet), elF-2, and elF-2B expression shows that GCN4 translation is inversely coupled to the level of elF-2.GTP.Met-tRNA(iMet) ternary complexes. Mol Cell Biol 1995, 15:6351-6363.

21. Chinchar VG, Dholakia JN: Frog virus 3-induced translational shut-off: activation of an elF-2 kinase in virus-infected cells. Virus Res 1989, 14:207-223.

22. Garner JN, Joshi B, Jagus R: Characterization of rainbow trout and zebrafish eukaryotic initiation factor 2alpha and its response to endoplasmic reticulum stress and IPNV infection. Dev Comp Immunol 2003, 27:217-231.

23. Hu CY, Zhang YB, Huang GP, Zhang QY, Gui JF: Molecular cloning and characterisation of a fish PKR-like gene from cultured CAB cells induced by UV-inactivated virus. Fish Shellfish Immunol 2004, 17:353-366.

24. Rothenburg S, Deigendesch N, Dittmar K, Koch-Nolte F, Haag F, Lowenhaupt K, Rich A: A PKR-like eukaryotic initiation factor 2alpha kinase from zebrafish contains Z-DNA binding domains instead of dsRNA binding domains. Proc Natl Acad Sci USA 2005, 102:1602-1607.

25. Bergan $V$, Jagus R, Lauksund S, Kileng O, Robertsen B: The Atlantic salmon Z-DNA binding protein kinase phosphorylates translation initiation factor 2 alpha and constitutes a unique orthologue to the mammalian dsRNA-activated protein kinase R. Febs J 2008, 275:184-197.

26. Su J, Zhu Z, Wang Y: Molecular cloning, characterization and expression analysis of the PKZ gene in rare minnow Gobiocypris rarus. Fish Shellfish Immunol 2008, 25:106-113.

27. Rothenburg S, Deigendesch N, Dey M, Dever TE, Tazi L: Double-stranded RNA-activated protein kinase PKR of fishes and amphibians: varying number of double-stranded RNA binding domains and lineage-specific duplications. BMC Biol 2008, 6:12

28. Zhu R, Zhang YB, Zhang QY, Gui JF: Functional domains and the antiviral effect of the double-stranded RNA-dependent protein kinase PKR from Paralichthys olivaceus. J Virol 2008, 82:6889-6901.

29. Deigendesch N, Koch-Nolte F, Rothenburg S: ZBP1 subcellular localization and association with stress granules is controlled by its Z-DNA binding domains. Nucleic Acids Res 2006, 34:5007-5020.

30. Takaoka A, Wang Z, Choi MK, Yanai H, Negishi H, Ban T, Lu Y, Miyagishi M, Kodama T, Honda K, et al: DAI (DLM-1/ZBP1) is a cytosolic DNA sensor and an activator of innate immune response. Nature 2007, 448:501-505.

31. Defilippis VR, Alvarado D, Sali T, Rothenburg S, Fruh K: Human cytomegalovirus induces the interferon response via the DNA sensor ZBP1. J Virol 2010, 84:585-598.
32. Langland JO, Cameron JM, Heck MC, Jancovich JK, Jacobs BL: Inhibition of PKR by RNA and DNA viruses. Virus Res 2006, 119:100-110.

33. Chang HW, Watson JC, Jacobs BL: The E3L gene of vaccinia virus encodes an inhibitor of the interferon-induced, double-stranded RNA-dependent protein kinase. Proc Natl Acad Sci USA 1992, 89:4825-4829.

34. Romano PR, Zhang F, Tan SL, Garcia-Barrio MT, Katze MG, Dever TE, Hinnebusch AG: Inhibition of double-stranded RNA-dependent protein kinase PKR by vaccinia virus E3: role of complex formation and the E3 $\mathrm{N}$-terminal domain. Mol Cell Biol 1998, 18:7304-7316, 29.

35. Beattie E, Tartaglia J, Paoletti E: Vaccinia virus-encoded elF-2a homolog the antiviral effect of interferon. Virology 1991, 183:419-422.

36. Dar AC, Sicheri F: X-ray crystal structure and functional analysis of vaccinia virus $\mathrm{K} 3 \mathrm{~L}$ reveals molecular determinants for PKR subversion and substrate recognition. Mol Cell 2002, 10:295-305.

37. Yu YX, Bearzotti $M$, Vende $P$, Ahne $W$, Bremont $M$ : Partial mapping and sequencing of a fish iridovirus genome reveals genes homologous to the frog virus 3 p31, p40 and human elF2alpha. Virus Res 1999, 63:53-63.

38. Essbauer S, Bremont M, Ahne W: Comparison of the elF-2alpha homologous proteins of seven ranaviruses (Iridoviridae). Virus Genes 2001, 23:347-359.

39. Majji S, LaPatra S, Long SM, Sample R, Bryan L, Sinning A, Chinchar VG: Rana catesbeiana virus Z (RCV-Z): a novel pathogenic ranavirus. Dis Aquat Organ 2006, 73:1-11.

40. Kawagishi-Kobayashi M, Silverman JB, Ung TL, Dever TE: Regulation of the protein kinase PKR by the vaccinia virus pseudosubstrate inhibitor K3L is dependent on residues conserved between the $\mathrm{K} 3 \mathrm{~L}$ protein and the PKR substrate elF2a. Mol Cell Biol 1997, 17:4146-4158.

41. Ito T, Marintchev A, Wagner G: Solution structure of human initiation factor elF2alpha reveals homology to the elongation factor eEF1B. Structure 2004, 12:1693-1704

42. Dever TE, Sripriya R, McLachlin JR, Lu J, Fabian JR, Kimball SR, Miller LK: Disruption of cellular translational control by a viral truncated eukaryotic translation initiation factor 2alpha kinase homolog. Proc Natl Acad Sci USA 1998, 95:4164-4169.

43. Kawagishi-Kobayashi M, Cao C, Lu J, Ozato K, Dever TE: Pseudosubstrate inhibition of protein kinase PKR by swine pox virus C8L gene product. Virology 2000, 276:424-434.

44. Cigan AM, Pabich EK, Feng L, Donahue TF: Yeast translation initiation suppressor sui2 encodes the alpha subunit of eukaryotic initiation factor 2 and shares sequence identity with the human alpha subunit. Proc Natl Acad Sci USA 1989, 86:2784-2788.

45. Dever TE, Chen JJ, Barber GN, Cigan AM, Feng L, Donahue TF, London IM Katze MG, Hinnebusch AG: Mammalian eukaryotic initiation factor 2 alpha kinases functionally substitute for GCN2 protein kinase in the GCN4 translational control mechanism of yeast. Proc Natl Acad Sci USA 1993, 90:4616-4620.

46. Carroll K, Elroy-Stein O, Moss B, Jagus R: Recombinant vaccinia virus K3L gene product prevents activation of double-stranded RNA-dependent, initiation factor 2 alpha-specific protein kinase. J Biol Chem 1993, 268:12837-12842.

47. Davies MV, Chang HW, Jacobs BL, Kaufman RJ: The E3L and K3L vaccinia virus gene products stimulate translation through inhibition of the double-stranded RNA-dependent protein kinase by different mechanisms. J Virol 1993, 67:1688-1692.

48. Nonato MC, Widom J, Clardy J: Crystal structure of the N-terminal segment of human eukaryotic translation initiation factor 2alpha. J Biol Chem 2002, 277:17057-17061

49. Rothenburg S, Seo EJ, Gibbs JS, Dever TE, Dittmar K: Rapid evolution of protein kinase PKR alters sensitivity to viral inhibitors. Nat Struct Mol Biol 2009, 16:63-70

50. Dar AC, Dever TE, Sicheri F: Higher-order substrate recognition of elF2alpha by the RNA-dependent protein kinase PKR. Cell 2005, 122:887-900

51. Seo EJ, Liu F, Kawagishi-Kobayashi M, Ung TL, Cao C, Dar AC, Sicheri F, Dever TE: Protein kinase PKR mutants resistant to the poxvirus pseudosubstrate K3L protein. Proc Natl Acad Sci USA 2008, 105:16894-16899.

52. Dever TE, Feng L, Wek RC, Cigan AM, Donahue TF, Hinnebusch AG: Phosphorylation of initiation factor 2 alpha by protein kinase GCN2 mediates gene-specific translational control of GCN4 in yeast. Cell 1992, 68:585-596. 
53. Reid GA, Schatz G: Import of proteins into mitochondria. Extramitochondrial pools and post-translational import ofmitochondrial protein precursors in vivo. J Biol Chem 1982, 257:13062-13067.

54. Edgar RC: MUSCLE: multiple sequence alignment with high accuracy and high throughput. Nucleic Acids Res 2004, 32:1792-1797.

55. Pollastri G, McLysaght A: Porter: a new, accurate server for protein secondary structure prediction. Bioinformatics 2005, 21:1719-1720.

doi:10.1186/1471-2180-11-56

Cite this article as: Rothenburg et al.: Characterization of a ranavirus inhibitor of the antiviral protein kinase PKR. BMC Microbiology 2011 11:56.

Submit your next manuscript to BioMed Central and take full advantage of:

- Convenient online submission

- Thorough peer review

- No space constraints or color figure charges

- Immediate publication on acceptance

- Inclusion in PubMed, CAS, Scopus and Google Scholar

- Research which is freely available for redistribution 